\title{
Investigation on Fire Retardancy Properties of Boric Acid Doped Textile Materials
}

\author{
F. AKARSLAN* \\ Süleyman Demirel University, Textile Engineering Department, Isparta, Turkey
}

\begin{abstract}
One way to better protect combustible materials against initiating fires is the use of flame retardants. Every day we come across new innovations particularly in the areas of flame retardant fibres and chemicals. This study investigates fire retardancy effect of boron on two cotton fabrics. Boron can soluble in water, colourless and capable of melting by heat. Boron is highly resistant to fire due to the melting temperature of $2300^{\circ} \mathrm{C}$. Because of this property, it is used as a flame-retardant material. The objective of this study was to examine the feasibility of imparting flame-retarding functions to different textile materials through the application of boric acid with impregnation methods. Different concentrations of boric acid nanoparticles were examined to optimize the flameretarding functions. Eventually, $45^{\circ}$ inclined combustion test are applied to the samples and examined the changes in strength of the samples. In this research; the aim is to bring in flame-retarding functions to different fabrics.
\end{abstract}

DOI: 10.12693/APhysPolA.128.B-403

PACS: 81.05.-t, 81.90.+c

\section{Introduction}

Fire hazards have a great socioeconomic impact on society. Textile materials that are readily combustible can serve as one of the ingredients in a fire and pose a serious threat to human life and property in fire accidents [1]. To provide additional protection from fires and to increase escape time when a fire occurs, methods to enhance the flame retardancy of consumer goods have been developed. They generally either lower ignition susceptibility or lower flame spread once ignition has occurred [2].

A large number of textiles and indoor decorations including carpets, curtains, wallpaper and so on, are all easy to burn. The demands for flame retardant textile fabrics have a steady growth for the past decades, and have become an urgent exigency. The flame retardant finishing of cotton fabric is the most commonly used method to produce flame retardant textile fabric [3]. Fire retardant chemicals are classified as halogen, phosphorus, nitrogen and inorganic compounds. Halogen and halogenantimony systems tend to be flame inhibitors, phosphorus and boron tend to enhance charring and formation of surface barrier layers, and metal hydroxides tend to be endothermic water-releasing systems [4]. The traditional flame retardants being used for cotton fabric are mainly flame retardant agent containing halogen and phosphorus. The use of halogen-based flame retardants to reduce the flammability of cotton is one of the most efficient ways of reducing the fire hazard. However, they have such noticeable disadvantages as the generation of emitting toxic and corrosive gases during thermal degradation, such as $\mathrm{HBr}$ and $\mathrm{HCl}$. In recent years, various efforts have been made to develop halogen-free flame retardant. Some compounds, containing phosphorus, silicon,

*e-mail: feyzaakarslan@sdu.edu.tr boron, nitrogen, and other miscellaneous elements, have gained much attention as flame retardant in the polymer materials to replace halogen-containing flame retardants. Boric acid and borate salts have been used as effective flame retardant additives, but they have been less studied than halogen, and phosphorus and other compounds [5]. The use of borates in enhancing the flame retardancy of polymeric materials was reported earlier in the 20th century. Borates are effective flame retardants because impenetrable glass coatings form when they thermally degrade. The glass coatings form on the surface, and can contribute to the intumescent effect, because they exclude oxygen and prevent further propagation of combustion. The water of hydration is lost by endothermic decomposition and therefore both dilutes and cools, by absorbing the thermal energy from the flame [6]. Boric acid was selected in this study because of its high flameretardancy effects and fewer environmental effects.

The objective of this study was to examine the feasibility of imparting flame-retarding functions to different textile materials through the application of boric acid with impregnation methods. Different concentrations of boric acid nanoparticles were examined to optimize the flame-retarding functions.

\section{Experimental}

\subsection{Materials}

Cotton fabric (100\%) was desized, scoured, and bleached (3/1 twill weave cotton fabric weighing $295 \mathrm{~g} / \mathrm{m}^{2}$ ) Boric acid is obtained by Eti Mine Works General Directorate.

\subsection{Fabric treatment}

Cotton fabrics were first impregnated in an aqueous solution containing a crosslinking agent, a catalyst and other additives. The impregnated fabrics were dried at $85^{\circ} \mathrm{C}$ and finally cured at a specified temperature in a 
curing oven manufactured by Werner Mathis. The fabric thus treated was finally subjected to one home laundering washing/drying cycle to remove the catalyst and other additives not bound to cotton according to AATCC Standard Method 124. The water temperature for laundering was approximately $40^{\circ} \mathrm{C}$. And then the treated samples were conditioned at $65 \pm 2 \%$ relative humidity and $20 \pm 1^{\circ} \mathrm{C}$ at least for $24 \mathrm{~h}$ prior to testing. The experimental plan is shown below Table I.

TABLE I

The experimental plan.

\begin{tabular}{c|c}
\hline \hline sample & amount of chemicals \\
\hline A0 & Reference sample A \\
A1 & $10 \mathrm{~g} / 1$ \\
A2 & $20 \mathrm{~g} / 1$ \\
A3 & $30 \mathrm{~g} / 1$
\end{tabular}

\subsection{Washing process}

In order to investigate the effect of multiple washings, the treated fabrics were washed five times after the finishing process in an Gyrowash washing machine with a short washing program at $40^{\circ} \mathrm{C}$ for 30 min with $4 \mathrm{~g} / \mathrm{L}$ of domestic detergent.

\subsection{Fabric performance evaluation}

The treated samples were conditioned at $65 \pm 2 \%$ relative humidity and $20 \pm 1{ }^{\circ} \mathrm{C}$ at least for $24 \mathrm{~h}$ prior to testing. $45^{\circ}$ inclined combustion test are applied to the samples according to DIN 54335. Color measurements of samples are done by spectrophotometer. Tensile strength of the samples were measured in accordance with TS 2150.

\section{Results}

Table II clearly shows the increases in the flamespreading times of the coated fabric systems with increasing concentration of boric acid nanoparticle content; these led to a corresponding increase in burn time. Table III shows the decrease in the tensile strength of the treated fabric.

TABLE II

Results associated with flamespreading times.

\begin{tabular}{c|c|c}
\hline \hline \multirow{2}{*}{ Sample } & \multicolumn{2}{|c}{ Flame-spreading time $[\mathrm{s}]$} \\
\cline { 2 - 3 } & weft & warp \\
\hline A0 & 2.5 & 2.4 \\
A1 & 3.5 & 3.4 \\
A2 & 3.8 & 3.6 \\
A3 & 4.2 & 3.9
\end{tabular}

TABLE III

Lloyd Tensile Strength Test Results.

\begin{tabular}{c|c|c|c}
\hline \hline \multicolumn{2}{c|}{ Sample } & $\begin{array}{c}\text { Tensile } \\
\text { strength [N] }\end{array}$ & $\begin{array}{c}\text { Elongation } \\
{[\%]}\end{array}$ \\
\hline \multirow{2}{*}{ A0 } & warp & 1524.3 & 44.692 \\
\cline { 2 - 4 } & weft & 752.95 & 16.310 \\
\hline \multirow{2}{*}{ A1 } & warp & 1406.8 & 42.157 \\
\cline { 2 - 4 } & weft & 638.58 & 16.256 \\
\hline \multirow{2}{*}{ A2 } & warp & 1323.7 & 42.082 \\
\cline { 2 - 4 } & weft & 612.98 & 15.663 \\
\hline \multirow{2}{*}{ A3 } & warp & 1125.9 & 41.571 \\
\cline { 2 - 4 } & weft & 610.52 & 14.680
\end{tabular}

\section{Conclusion}

The aim of this study was to investigate the application of boric acid to cotton fabrics for the purpose of imparting flame-retardant. It was determined that improved fire retardance, reduction in tensile strength.

Today, the growing turmoil, to increase the risk of fire, life and property safety is decreasing. Therefore, the use of flame retardant textiles are inevitably increases. The aim of this study was to examine the feasibility of imparting flame-retarding functions to different textile materials through the application of boric acid with impregnation methods.

\section{References}

[1] R. Gemci, G. Gülşen, Electr. J. Textile Techn. 4, 1 (2010) (in Turksh)

[2] N. Selvakumar, A. Azhagurajan, T.S. Natarajan, M. Mohideen Abdul Khadir, J. Appl. Polym. Sci. 126, 614 (2012).

[3] N. Harımdar, Lic.Th., Süleyman Demirel Üniversitesi, Fen Bilimleri Enstitüsü, Tekstil Mühendisliği Anabilim dalı, Isparta 2012.

[4] G.Ö. Çakal, Z. Göğebakan, S. Coşkun, Tekstil ve Konfeksiyon 3, 265 (2011).

[5] K. Xie, A. Gao, Y. Zhang, Carbohyd. Polym. 98, 706 (2013).

[6] C. Martin, J.C. Ronda, V. Cadiz, Polym. Degrad. Stabil. 91, 747 (2006). 